\title{
純曲げの作用する閉断面円筒シェルの円環を基準とする 3 次元有限変形解析 \\ THREE-DIMENSIONAL FINITE DEFORMATION ANALYSIS OF A CYLINDRICAL SHELL SUBJECTED TO PURE BENDING USING TORUS COORDINATES
}

\author{
上村充 範*，松 岡 理**，山田耕司***，松井徹哉**** \\ Mitsunori KAMIMURA, Osamu MATSUOKA, Koji YAMADA \\ and Tetsuya MATSUI
}

\begin{abstract}
This paper is concerned with three-dimensional finite deformation analysis of a closed circular cylindrical shell subjected to pure bending. It is expected in this case that the element of the cylindrical shell will be deformed approximately to the torus shape. Then, in this paper, the torus coordinates are employed to indicate the deformed state of the shell. This approach using the torus coordinates makes the analysis simple. This paper also investigates whether the shell collapses by the Brazier buckling or by the plastic yielding due to local stresses. It is shown that the Brazier buckling occurs only for a very thin shell. The collapse of the moderate or thick shell is followed by the plastic yielding. This indicates the importance of investigating the local stress as well as the Brazier buckling.
\end{abstract}

Keywords: three-dimensional finite deformation analysis, cylindrical shell, pure bending torus coordinates, Brazier buckling, plastic yielding

3 次元有限变形解析，円简シェル，純曲げ，円瑾座標，屆服座屈，塑性降伏

\section{1. 序}

通常，有限变形を考慮した解析をおこなう場合には，変形後の状態は 未定であるため，变形前の自然状熊を基準として変形後の状態を表示し ている.しかし，座標系としては単純な円筒座標系を採用し純曲げを作 用させても，変形前の円筒座標を基準に採り解析をおこなうと，かなり 複雑な解が得られて，本来ならば円筒軸上で一定であるべき断面変形と モーメントが変化する結果となり，何らかの修正が必要となる． ${ }^{8)}$

この修正法として本論文では軸方向の曲率変化に着目する. 円筒シェ ルに純曲げが作用すると，シェルは近似的に曲率一定な円環 (トーラス) 形状の一要素になる.そこで, 变形前の形状を円筒座標により，变形後の 形状を円環座標と同座標系の变位成分によって表わして，純曲げの大き さより円環軸線の曲率を，验合と境界条件より変位成分を決める解法が 考えられる.これによると, 主要な变形は座標系で考慮されたことにな り，断面内における $2 つ の$ 座標パラメータのみに関する剑合式が得られ， 变形後の形状を円筒座標を基準とする解析に比べて簡潔なものとなる.
本論文では，变形後の形状を基準に円環座標を探り，3 次元有限变形 理論 6) 13)によって, 純曲げの作用する円筒シェルの安定問題につい て解析する.

純曲げによる屈服座届，および，純曲げによる曲げ主応力と純曲げの 増大につれて円形断面が棈円化することにより生じるリング方向曲げ主 応力との組み合わせによる局所的応力の降伏について述べ，極薄円筒 シェルにおいては屈服座屈の先行によるシェルの破壤がみられるが，通 常のシェルでは，変形後の応力の組み合わせによる降伏応力によって局 部座届が先行し，円筒シェルが破坥に至るという結果を得ている。

純曲げの作用する円筒シェルの設計に漈し，断面の楕円化に伴う曲げ 用性の诚少効果，すなわち Brazier 効果を考慮した曲げ座屈のみならず， 有限变形理論に基つく軸方向曲げ応力と, 円弧方向曲げ応力の組み合わ せによる応力の検討が重要であることを述べている.

变形後の形状が近似的に推定できることによって本解析手法が適用で きる例として, 外圧の作用する部分球形シェルを挙げることができる.
* 名古屋大学大学院工学研究科 大学院生. 修士 (工学)

** 中部大学工学部建築学科教授. 工博

*** 豊田工業高等等門学校 講師・博士 (工学)

**** 名古屋大学大学院工学研究科 教授.工博
Graduate Student, Dept of Architecture, Nagoya Univ., M. Eng.

Prof., Dept. of Architecture, Chubu Univ., Dr. Eng.

Lecturer, Toyota National College of Technology, Dr. Eng.

Prof., Dept. of Architecture, Nagoya Univ., Dr. Eng. 


\section{2. 本諭で用いる钎号}

变形前の円筒座標と基㴶の円橓座標および变形後の表示を区別するた

め, 円渨座標系の成分は一，变形後の成分は $=$ で表示する.

\begin{tabular}{|c|c|c|}
\hline$r, \theta, \phi$ & $:$ & 円筒座標, 円環座標パラメータ \\
\hline 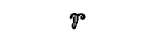 & : & 円简座標系位置ベクトル \\
\hline $\bar{P}$ & $:$ & 円環座標系位置ベクトル \\
\hline$\overline{\overline{\boldsymbol{T}}}$ & : & $\bar{p}+\boldsymbol{u}$ \\
\hline$u$ & : & 変位ベクトル \\
\hline$R$ & : & $\begin{array}{l}\text { 円環中心線の曲率半径 } \\
\text { または円筒座標軸 } Z, Z=R \phi\end{array}$ \\
\hline$a_{i}$ & : & rについての共変基底ベクトル \\
\hline $\bar{\alpha}_{i}$ & : & テ゚についての共変基底べクトル \\
\hline$\overline{\bar{a}}_{i}$ & : & 礼ついての共変基底べクトル \\
\hline$a_{i j}, \bar{a}_{i j}, \overline{\bar{a}}_{i j}$ & : & 共変計量テンソル \\
\hline$a^{i j}, \bar{a}^{i j}, \overline{\bar{a}}^{i j}$ & : & 区変計量テンソル \\
\hline$\sigma^{i j}$ & : & $\begin{array}{l}\text { 変形前の形状に基づいて表わされた } \\
2 \text { 階反変忘カテンソル }\end{array}$ \\
\hline$\overline{\bar{\sigma}}^{i j}$ & : & $\begin{array}{l}\text { 変形後の状能の円環座標系における } \\
2 \text { 階反変応カテンソル }\end{array}$ \\
\hline ,i & : & 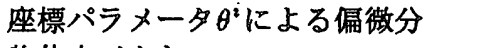 \\
\hline$X$ & 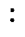 & 物体カベクトル \\
\hline$r_{1}, r_{2}$ & : & シェル内外半径 \\
\hline$r_{0}, t_{0}$ & : & シェル平均半径, シェル厚 \\
\hline$P, Q$ & ${ }^{\circ}$ & $\begin{array}{l}r_{1}^{2}+r_{2}^{2}, r_{1} r_{2} \\
\frac{Q^{2}}{}\end{array}$ \\
\hline & * & $P^{2}-4 Q^{2}$ \\
\hline
\end{tabular}

\section{3. 純曲げの作用する円筒シェルの解析}

純曲け゚の作用する円筒シェルは，第一近似としてまず円環 (トーラス) 形状となることが予想される.この円檈座標を基準に探り，验合式と境 界条件を満たす变位を円環座標系の成分として求刍主要な变形は座 標系で考慮されることになり，队環軸方向の変位を扱うことなく円形断 面における 2 個の未知変位成分により解析を進めることができる. 変形 状態の鈎合式を円環座標系によって表わし, 更に变形状態の応力をキル ヒホフ応力によって表わせぽ, 純曲け゚の作用する円筒シェルの円壊座標 を基準とする变形後の验合式を放射方向と円周方向について導くことが できる. また, 变位成分を円周方向にフーリエ展開し, これらを用いて 変形前後の計量テンソルの差より得られるひずみを物理量で表わして, 态力ーひずみ関係より応力を求め敛合式に代入すると，曲价荷重に関する 次数と円周方向のフーリエ展開次数について俆合式を分離することがで きる. そして，各次数の釣合式を摄動法 (Perturbation Method) 的に 解く．まず物体力を零とした線形猃合式を解き，これを基に非線形の钻 合式に現れる低次解からくる非線形項を物体力とみなしてその验合式を 解く.この操作を順次絽り返していくことで高次の解を導く.

\section{1. 座洯の衰示}

ひずみテンソルは変形前後の計量テンソルの差によって表示されるた め,ここでは各座標系における位置べクトルの表示法と, 計量テンソル を示す. 変形前後において, それぞれの中心軸の長さが変わらないとし て円筒座標と円㻴座標を表示する。

\subsection{1 円筒座標}

- 位置ベクトル

$$
\mathscr{r}=(R+r \cos \theta) \dot{3}+(r \sin \theta) \dot{j}+(R \phi) \mathbb{k}
$$

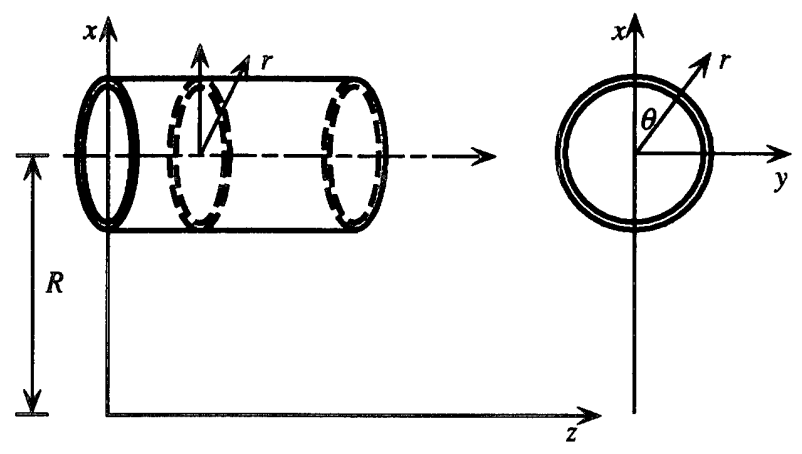

図－1：円筒座標

- 基底ベクトル

$$
\begin{aligned}
& \boldsymbol{a}_{1}=\frac{\partial \boldsymbol{r}}{\partial \boldsymbol{r}}=\cos \theta \boldsymbol{i}+\sin \theta \boldsymbol{j} \\
& \mathfrak{a}_{2}=\frac{\partial \boldsymbol{r}}{\partial \theta}=-r \sin \theta \boldsymbol{i}+r \cos \theta \boldsymbol{j} \\
& \boldsymbol{a}_{3}=\frac{\partial \boldsymbol{r}}{\partial \phi}=R \boldsymbol{k}
\end{aligned}
$$

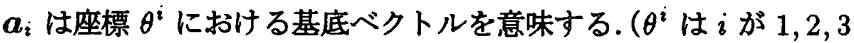
のときそれれそれ $r, \theta, \phi$ 座標に対応)

・計量テンソル

$$
\begin{aligned}
& a_{11}=1 \\
& a_{22}=r^{2} \\
& a_{33}=R^{2} \\
& a_{12}=a_{13}=a_{23}=0 \\
& a=\operatorname{det}\left|a_{i j}\right|=r^{2} R^{2}
\end{aligned}
$$

3.1.2 円環 (トーラス) 座標

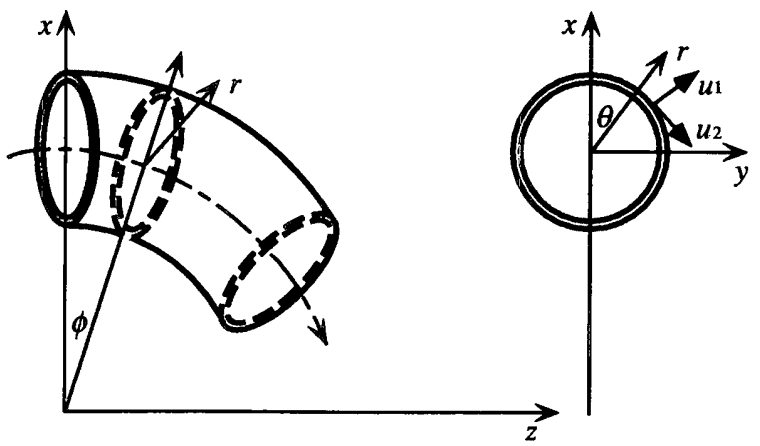

図一 2: 円環座標

・位㯰ベクトル

$$
\begin{aligned}
\overline{\boldsymbol{r}}= & (R+r \cos \theta) \cos \phi \boldsymbol{i}+r \sin \theta \boldsymbol{j} \\
& +(R+r \cos \theta) \sin \phi \boldsymbol{k}
\end{aligned}
$$

- 基底ベクトル

$$
\begin{aligned}
\bar{a}_{1} & =(\cos \theta \cos \phi) i+(\sin \theta) j+(\cos \theta \sin \phi) k \\
& =e_{1}
\end{aligned}
$$




$$
\begin{aligned}
\overline{\boldsymbol{a}}_{2} & =(-r \sin \theta \cos \phi) \boldsymbol{i}+(r \cos \theta) \boldsymbol{j}+(-r \sin \theta \sin \phi) \boldsymbol{k} \\
& =r \boldsymbol{e}_{2} \\
\overline{\boldsymbol{a}}_{3} & =(R+r \cos \theta)(-\sin \phi \boldsymbol{i}+\cos \phi \boldsymbol{k}) \\
& =(R+r \cos \theta) \boldsymbol{e}_{3}
\end{aligned}
$$

$\boldsymbol{e}_{1}, \boldsymbol{e}_{2}, \boldsymbol{e}_{3}$ は，それぞれ円環（トーラス）座標における単位ベクトル である.

・計量テンソル

$$
\begin{aligned}
& \bar{a}_{11}=1 \\
& \bar{a}_{22}=r^{2} \\
& \bar{a}_{33}=(R+r \cos \theta)^{2} \\
& \bar{a}=\operatorname{det}\left|\bar{a}_{i j}\right|=r^{2}(R+r \cos \theta)^{2}
\end{aligned}
$$

\section{1 .3 変形後}

純曲げの作用する円筒シェルの第一近似形状として円筒が円環になっ た状热だけでは内外の表面における応力の境界条件は満たされていない， これを满足するには補助的変位を加える必要がある．本論による有限変 形解析では主な变形を座標系で考慮し，円環座標系における销合を満た すために断面内での微小変位を考える．ただし，純曲げによる圧縮帯の 下秝の局所的座屈は考慮せず, トーラスの軸対称問題として解析する.

円環座標系における変位ベクトルを $\boldsymbol{u}$ とする.

$$
\boldsymbol{u}=u_{1} \boldsymbol{e}_{1}+u_{2} \boldsymbol{e}_{2}
$$

・变形後の位置ベクトル

$$
\overline{\overline{\boldsymbol{r}}}=\overline{\boldsymbol{r}}+\boldsymbol{u}
$$

・基底ベクトル

$$
\begin{aligned}
& \overline{\overline{\boldsymbol{a}}}_{1}=\frac{\partial \overline{\overline{\boldsymbol{r}}}}{\partial r}=\left(1+u_{1,1}\right) \boldsymbol{e}_{1}+u_{2,1} \boldsymbol{e}_{2} \\
& \overline{\overline{\boldsymbol{a}}}_{2}=\frac{\partial \overline{\overline{\boldsymbol{r}}}}{\partial \theta}=\left(u_{1,2}-u_{2}\right) \boldsymbol{e}_{1}+\left(r+u_{2,2}+u_{1}\right) \boldsymbol{e}_{2} \\
& \overline{\overline{\boldsymbol{a}}}_{3}=\frac{\partial \overline{\overline{\boldsymbol{r}}}}{\partial \phi}=\left(R+r \cos \theta+u_{1} \cos \theta-u_{2} \sin \theta\right) \boldsymbol{e}_{3}
\end{aligned}
$$

・計量テンソル

$$
\begin{aligned}
& \overline{\bar{a}}_{11}=\left(1+u_{1,1}\right)^{2}+\left(u_{2,1}\right)^{2} \\
& \overline{\bar{a}}_{12}=\left(1+u_{1,1}\right)\left(u_{1,2}-u_{2}\right)+u_{2,1}\left(r+u_{1}+u_{2,2}\right) \\
& \overline{\bar{a}}_{22}=\left(u_{1,2}-u_{2}\right)^{2}+\left(r+u_{1}+u_{2,2}\right)^{2} \\
& \overline{\bar{a}}_{33}=\left(R+r \cos \theta+u_{1} \cos \theta-u_{2} \sin \theta\right)^{2} \\
& \overline{\bar{a}}_{13}=\overline{\bar{a}}_{23}=0 \\
& \overline{\bar{a}}=\operatorname{det}\left|\overline{\bar{a}}_{i j}\right|=\left\{\overline{\bar{a}}_{11} \overline{\bar{a}}_{22}-\left(\overline{\bar{a}}_{12}\right)^{2}\right\} \overline{\bar{a}}_{33}
\end{aligned}
$$

3.2. 验合式

有限変形の基礎式 6 ) より純曲げの作用する円筒シェルの物体力を零と した変形後の釣合式が得られる.ここで, $i=1 \sim 3$ において $\theta^{i}$ は $r, \theta, \phi$ 座標に対応する.

$$
\frac{\partial}{\partial \theta^{i}}\left(\sqrt{\overline{\bar{a}}} \overline{\bar{\sigma}}^{i j} \overline{\bar{a}}_{j}\right)=0
$$

キルヒホフ応力変換 $\sqrt{\overline{\bar{a}}} \overline{\bar{\sigma}}^{i j}=\sqrt{a} \sigma^{i j}$ を用いると

$$
\frac{\partial}{\partial \theta^{i}}\left(\sqrt{a} \sigma^{i j} \overline{\bar{a}}_{j}\right)=0
$$

\section{ここで 2 陛反变応カテンソル量を物理量で表わす次式を用いる.}

$$
\begin{aligned}
& \sigma^{i j}=\sqrt{\frac{a^{i i}}{a_{j j}}} \sigma^{i j} \\
& \frac{\partial}{\partial \theta^{i}}\left\{\left(\sqrt{a} \sqrt{\frac{a^{i i}}{a_{j j}}} \sigma^{i j}\right) \overline{\bar{a}}_{j}\right\}=0
\end{aligned}
$$

(o)

忘力の物理量 $\sigma^{i j}$ を改めて $\sigma_{i j}$ と書き表わして次式を得る.

$$
\begin{array}{r}
R\left(r \sigma_{11} \overline{\overline{\boldsymbol{a}}}_{1}+\sigma_{12} \overline{\overline{\boldsymbol{a}}}_{2}\right)_{, 1}+R\left(\sigma_{21} \overline{\overline{\boldsymbol{a}}}_{1}+\frac{1}{r} \sigma_{22} \overline{\overline{\boldsymbol{a}}}_{2}\right)_{, 2} \\
-\frac{1}{R}\left(r \sigma_{33} \overline{\overline{\boldsymbol{a}}}_{3}\right)_{, 3}=0
\end{array}
$$

变形後の基底ベクトル $\overline{\overline{\boldsymbol{a}}}_{\boldsymbol{i}}$ は円筒座標を基漼に変位べクトルをとって 得られたのものでも，円環座標を介して得られたのものでもよい。ここ では，円墂座標を考慮することによって主な変形を含んだ基底べクトル を代入することで，主軸方向に関する验り合いは考慮されたことになり， 次に示すようなトーラス断面内における微小变位に関する簡素化された 2 つの釣合式を解くことになる.

- 放射方向

$$
\begin{aligned}
& \sigma_{11,1}+\frac{1}{r}\left(\sigma_{11}-\sigma_{22}\right)+\frac{1}{r} \sigma_{12,2} \\
& +\left\{\sigma_{11,1}+\frac{1}{r}\left(\sigma_{11}+\sigma_{12,2}\right)\right\} u_{1,1}+\sigma_{11} u_{1,11} \\
& +\frac{1}{r}\left(\sigma_{12,1}+\frac{1}{r} \sigma_{22,2}\right)\left(u_{1,2}-u_{2}\right) \\
& +\frac{2}{r} \sigma_{12}\left(u_{1,12}-u_{2,1}\right)+\frac{1}{r^{2}} \sigma_{22}\left(u_{1,22}-2 u_{2,2}-u_{1}\right) \\
& -\frac{1}{R} \sigma_{33} \cos \theta-\frac{r}{R^{2}} \sigma_{33} \cos ^{2} \theta \\
& -\frac{1}{R^{2}} \sigma_{33} \cos \theta\left(u_{1} \cos \theta-u_{2} \sin \theta\right)=0
\end{aligned}
$$

- 円周方向

$$
\begin{aligned}
& \sigma_{12,1}+\frac{2}{r} \sigma_{12}+\frac{1}{r} \sigma_{22,2} \\
& +\left\{\sigma_{11,1}+\frac{1}{r}\left(\sigma_{11}+\sigma_{12,2}\right)\right\} u_{2,1}+\sigma_{11} u_{2,11} \\
& +\frac{1}{r}\left(\sigma_{12,1}+\frac{1}{r} \sigma_{22,2}\right)\left(u_{2,2}+u_{1}\right) \\
& +\frac{2}{r} \sigma_{12}\left(u_{2,12}+u_{1,1}\right)+\frac{1}{r^{2}} \sigma_{22}\left(u_{2,22}+2 u_{1,2}-u_{2}\right) \\
& +\frac{1}{R} \sigma_{33} \sin \theta+\frac{r}{R^{2}} \sigma_{33} \sin \theta \cos \theta \\
& +\frac{1}{R^{2}} \sigma_{33} \sin \theta\left(u_{1} \cos \theta-u_{2} \sin \theta\right)=0
\end{aligned}
$$

\section{3. 計量テンソルによるひずみ}

数学的ひずみ $e_{i j}=\frac{1}{2}\left(\overline{\bar{a}}_{i j}-a_{i j}\right)$ より，物理的ひずみ $\varepsilon_{i j}$ は次の ようになる.

$$
\begin{aligned}
\varepsilon_{11} & =u_{1,1}+\frac{1}{2}\left\{\left(u_{1,1}\right)^{2}+\left(u_{2,1}\right)^{2}\right\} \\
\varepsilon_{12}= & \frac{1}{2}\left\{u_{2,1}+\frac{1}{r}\left(u_{1,2}-u_{2}\right)\right\} \\
& +\frac{1}{2 r}\left\{u_{1,1}\left(u_{1,2}-u_{2}\right)+u_{2,1}\left(u_{2,2}+u_{1}\right)\right\}
\end{aligned}
$$




$$
\begin{aligned}
\varepsilon_{22}= & \frac{1}{r}\left(u_{1}+u_{2,2}\right)+\frac{1}{2 r^{2}}\left\{\left(u_{1,2}-u_{2}\right)^{2}+\left(u_{2,2}+u_{1}\right)^{2}\right\} \\
\varepsilon_{33}= & \frac{r}{R} \cos \theta \\
& +\frac{1}{R}\left(u_{1} \cos \theta-u_{2} \sin \theta\right)+\frac{r^{2}}{2 R^{2}} \cos ^{2} \theta \\
& +\frac{r}{R^{2}} \cos \theta\left(u_{1} \cos \theta-u_{2} \sin \theta\right) \\
& +\frac{1}{2 R^{2}}\left(u_{1} \cos \theta-u_{2} \sin \theta\right)^{2} \\
\varepsilon_{13} & =\varepsilon_{31}=\varepsilon_{23}=\varepsilon_{32}=0
\end{aligned}
$$

变位ベクトルの放射方向成分 $u_{1}$ および円周方向成分 $u_{2}$ を, 円周方 向にフーリエ展開すると次のようにおける.

$$
\begin{aligned}
u_{1}= & U_{11} \cos \theta+U_{20}+U_{22} \cos 2 \theta \\
& +\left(U_{31}+U\right) \cos \theta+U_{33} \cos 3 \theta \\
u_{2}= & V_{11} \sin \theta+V_{22} \sin 2 \theta \\
& +\left(V_{31}-U\right) \sin \theta+V_{33} \sin 3 \theta
\end{aligned}
$$

ここで, $U_{i j}$ および $V_{i j}$ の $i$ は幾何学的非線形からくるパラメータ $\alpha\left(=1 / R=M_{0} / E I\right)$ の次数を, $j$ はフーリエ展開炊数を意味する. また, $U$ は円謤の曲事半径 $R$ の変化によるものであり, $M_{0}$ は純曲げ 荷重, $I$ は円形断面二次モーメントである. なお, 本解析では $\alpha^{3}$ まで の解を求めることにする.

以上より，ひずみを改めて表示すると次のようになる.

$$
\begin{aligned}
\varepsilon_{11}= & U_{11} \cos \theta \\
+ & U_{20,1}+\frac{1}{4}\left\{\left(U_{11,1}\right)^{2}+\left(V_{11,1}\right)^{2}\right\} \\
& +\left[U_{22,1}+\frac{1}{4}\left\{\left(U_{11,1}\right)^{2}+\left(V_{11,1}\right)^{2}\right\}\right] \cos 2 \theta \\
+ & \left(U_{31,1}+U_{11,1} U_{20,1}+\frac{1}{2} U_{11,1} U_{22,1}\right. \\
& \left.+\frac{1}{2} V_{11,1} V_{22,1}\right) \cos \theta \\
+ & \left(U_{33,1}+\frac{1}{2} U_{11,1} U_{22,1}-\frac{1}{2} V_{11,1} V_{22,1}\right) \cos 3 \theta \\
= & \varepsilon_{1111} \cos \theta+\varepsilon_{1120}+\varepsilon_{1122} \cos 2 \theta \\
& +\varepsilon_{1131} \cos \theta+\varepsilon_{1133} \cos 3 \theta \\
\varepsilon_{12}= & \frac{1}{2}\left\{V_{11,1}-\frac{1}{r}\left(U_{11}+V_{11}\right)\right\} \sin \theta \\
+ & {\left[\frac{1}{2}\left\{V_{22,1}-\frac{1}{r}\left(2 U_{22}+V_{22}\right)\right\}\right.} \\
& \left.\quad-\frac{1}{4 r}\left(U_{11,1}-V_{11,1}\right)\left(U_{11}+V_{11}\right)\right] \sin 2 \theta \\
+ & {\left[\frac{1}{2}\left\{V_{31,1}-\frac{1}{r}\left(U_{31}+V_{31}\right)\right\}-\frac{1}{4 r} U_{11,1}\left(2 U_{22}+V_{22}\right)\right.} \\
& \quad-\frac{1}{4 r} V_{11,1}\left(U_{22}+2 V_{22}-2 U_{20}\right) \\
+ & \left.+\frac{1}{4 r}\left(U_{11}+V_{11}\right)\left(U_{22,1}+V_{22,1}-2 U_{20,1}\right)\right] \sin \theta \\
+ & {\left[\frac{1}{2}\left\{V_{33,1}-\frac{1}{r}\left(3 U_{33}+V_{33}\right)\right\}-\frac{1}{4 r} U_{11,1}\left(2 U_{22}+V_{12}\right)\right.} \\
& \left.\frac{1}{r}\left(U_{11}+V_{11}+V_{11}\right)\left(U_{22,1}-V_{22,1}\right)\right] \sin 3 \theta \\
& +\varepsilon_{1222} \sin 2 \theta \\
& \left.+V_{22}\right) \\
& \\
&
\end{aligned}
$$

$$
\begin{aligned}
+ & \frac{1}{r} U_{20}+\frac{1}{2 r^{2}}\left(U_{11}+V_{11}\right)^{2} \\
+ & \frac{1}{r}\left(U_{22}+2 V_{22}\right) \cos 2 \theta \\
+ & \left\{\frac{1}{r}\left(U_{31}+V_{31}\right)\right. \\
& \left.\quad-\frac{1}{2 r^{2}}\left(U_{11}+V_{11}\right)\left(2 U_{20}+3 U_{22}+3 V_{22}\right)\right\} \cos \theta \\
+ & \left\{\frac{1}{r}\left(U_{33}+3 V_{33}\right)\right. \\
& \left.\quad-\frac{1}{2 r^{2}}\left(U_{11}+V_{11}\right)\left(U_{22}-V_{22}\right)\right\} \cos 3 \theta \\
= & \varepsilon_{2211} \cos \theta+\varepsilon_{2220}+\varepsilon_{2222} \cos 2 \theta \\
& +\varepsilon_{2231} \cos \theta+\varepsilon_{2233} \cos 3 \theta \\
= & \frac{r}{R} \cos \theta \\
+ & \frac{U}{R}+\frac{r^{2}}{4 R^{2}}+\frac{1}{2 R}\left(U_{11}-V_{11}\right) \\
+ & \frac{1}{2 R}\left\{\frac{r^{2}}{2 R}+\left(U_{11}+V_{11}\right)\right\} \cos 2 \theta \\
+ & {\left[\frac{1}{R}\left\{U_{20}+\frac{1}{2}\left(U_{22}-V_{22}\right)\right\}+\frac{r}{R^{2}}\left\{\frac{1}{2}\left(U_{11}-V_{11}\right)\right.\right.} \\
& \left.\left.+\frac{1}{4}\left(U_{11}+V_{11}\right)+U\right\}\right] \cos \theta \\
+ & \frac{1}{2 R}\left\{\left(U_{22}+V_{22}\right)+\frac{r}{2 R}\left(U_{11}+V_{11}\right)\right\} \cos 3 \theta \\
= & \varepsilon_{3311} \cos \theta+\varepsilon_{3320}+\varepsilon_{3322} \cos 2 \theta \\
& +\varepsilon_{3331} \cos \theta+\varepsilon_{3333} \cos 3 \theta
\end{aligned}
$$

次式は物理量で表示された応力とひずみの各成分の関係である.

$$
\begin{aligned}
\sigma_{i j p q} & =2 G\left(\varepsilon_{i j p q}+\frac{\nu}{1-2 \nu} e_{p q} \delta_{i j}\right) \\
e_{p q} & =\varepsilon_{11 p q}+\varepsilon_{22 p q}+\varepsilon_{33 p q}
\end{aligned}
$$

ここで, $p, q$ は, $\alpha$ の欧数およびフーリエ展開次数を意味する.

$$
\begin{aligned}
\sigma_{11}= & \sigma_{1111} \cos \theta+\sigma_{1120}+\sigma_{1122} \cos 2 \theta \\
& +\sigma_{1131} \cos \theta+\sigma_{1133} \cos 3 \theta \\
\sigma_{12}= & \sigma_{1211} \sin \theta+\sigma_{1222} \sin 2 \theta \\
& +\sigma_{1231} \sin \theta+\sigma_{1233} \sin 3 \theta \\
\sigma_{22}= & \sigma_{2211} \cos \theta+\sigma_{2220}+\sigma_{2222} \cos 2 \theta \\
& +\sigma_{2231} \cos \theta+\sigma_{2233} \cos 3 \theta \\
\sigma_{33}= & \sigma_{3311} \cos \theta+\sigma_{3320}+\sigma_{3322} \cos 2 \theta \\
& +\sigma_{3331} \cos \theta+\sigma_{3333} \cos 3 \theta
\end{aligned}
$$

\section{4. 解法およひ解}

変位成分と構成方程式により变位成分表示された応力成分を式 $(5)(6)$ に代入して猃合式を $\alpha$ とフーリエ展開次数 $n$ で展開し掫動法的解法に よって解く，得られた微分方程式を解くにあたり，シェルの内外境界面 は自由面である (すなわち, $r=r_{1}, r_{2}$ において $\sigma_{1111}=\sigma_{1211}=0$ ) という境界条件を用いる. 以下に，各次数の验合式とその解を示寸.

$$
\begin{aligned}
& \bullet \alpha^{1}, n=1 \\
& U_{11,11}+\frac{1}{r} U_{11,1}-\frac{2}{r^{2}}\left(U_{11}+V_{11}\right) \\
& +\frac{1}{1-2 \nu}\left\{U_{11,1}+\frac{1}{r}\left(U_{11}+V_{11}\right)\right\}_{, 1}+\frac{2 \nu}{1-2 \nu} \frac{1}{R}=0 \\
& V_{11,11}+\frac{1}{r} V_{11,1}-\frac{2}{r^{2}}\left(U_{11}+V_{11}\right) \\
& -\frac{1}{1-2 \nu} \frac{1}{r}\left\{U_{11,1}+\frac{1}{r}\left(U_{11}+V_{11}\right)\right\}-\frac{2 \nu}{1-2 \nu} \frac{1}{R}=0
\end{aligned}
$$




$$
\begin{aligned}
& U_{11}=V_{11}=-\frac{1}{2} \frac{\nu}{R} r^{2} \\
& \sigma_{33}=\sigma_{3311} \cos \theta=2 G(1+\nu) \frac{r}{R} \cos \theta \\
& \sigma_{11}=\sigma_{12}=\sigma_{22}=0
\end{aligned}
$$

軸応力 $\sigma_{33}$ によるモーメントを求めると, 線形解においては初期モー メント $M_{0}$ に一票している.

$$
\int_{0}^{2 \pi} \int_{r_{1}}^{r_{2}} \sigma_{33} r \cos \theta r d \theta d r=\frac{E}{R} I=M_{0}
$$

( $I$ : 円形断面二次モーメント)

$\bullet \alpha^{2}, n=0$

線形解による非線形項を物体力として解く.

$$
\begin{aligned}
& U_{20,11}+\frac{1}{r} U_{20,1}-\frac{1}{r^{2}} U_{20}-\frac{1-2 \nu-4 \nu^{2}}{2(1-2 \nu)} \alpha^{2} r=0 \\
& U_{20}=-\frac{3+2 \nu}{16(1-\nu)} \alpha^{2} r_{1}{ }^{2} r_{2}{ }^{2} r^{-1} \\
&- \frac{(1-2 \nu)(3+2 \nu)}{16(1-\nu)} \alpha^{2}\left(r_{1}{ }^{2}+r_{2}{ }^{2}\right) r \\
&-\nu U \alpha r+\frac{1-2 \nu-4 \nu^{2}}{16(1-\nu)} \alpha^{2} r^{3}
\end{aligned}
$$

$\bullet \alpha^{2}, n=2$

$$
\begin{aligned}
& U_{22,11}+\frac{1}{r} U_{22,1}-\frac{1}{r^{2}}\left(5 U_{22}+4 V_{22}\right) \\
& +\frac{1}{1-2 \nu}\left\{U_{22,1}+\frac{1}{r}\left(U_{22}+2 V_{22}\right)\right\}_{, 1}-\alpha^{2} r=0 \\
& V_{22,11}+\frac{1}{r} V_{22,1}-\frac{1}{r^{2}}\left(4 U_{22}+5 V_{22}\right) \\
& -\frac{1}{1-2 \nu} \frac{2}{r}\left\{U_{22,1}+\frac{1}{r}\left(U_{22}+2 V_{22}\right)\right\}+\alpha^{2} r=0
\end{aligned}
$$$$
U_{22}=\frac{1}{2}\left[a_{221} r^{-3}-\frac{2(1-\nu)}{1-2 \nu} d_{221} r^{-1}+b_{222} r\right.
$$$$
\left.+\left\{\frac{\alpha^{2}}{6}-\frac{2 \nu}{3(1-2 \nu)} d_{222}\right\} r^{3}\right]
$$$$
V_{22}=\frac{1}{2}\left[a_{221} r^{-3}+d_{221} r^{-1}-b_{222} r\right.
$$$$
\left.-\left\{\frac{\alpha^{2}}{3}+\frac{3-2 \nu}{3(1-2 \nu)} d_{222}\right\} r^{3}\right]
$$$$
a_{221}=\frac{\alpha^{2}}{2}(1+\nu) \frac{Q^{4}}{P}\{1+4 A\}
$$$$
b_{222}=-\frac{\alpha^{2}}{2}(1+\nu) P\{1+3 A\}
$$$$
d_{221}=\alpha^{2}(1-2 \nu)(1+\nu) Q^{2}\{1+3 A\}
$$$$
d_{222}=-\alpha^{2}(1-2 \nu)\left\{\frac{\nu}{2}+3(1+\nu) A\right\}
$$

$\bullet \alpha^{3}, n=1$

\footnotetext{
線形解および 2 次の非線形解を考慮して解く.
}

$$
\begin{aligned}
& U_{31,11}+\frac{1}{r} U_{31,1}-\frac{2}{r^{2}}\left(U_{31}+V_{31}\right) \\
& +\frac{1}{1-2 \nu}\left\{U_{31,1}+\frac{1}{r}\left(U_{31}+V_{31}\right)\right\}_{, 1} \\
& -\frac{2\left(1-2 \nu-2 \nu^{2}\right) U \alpha^{2}}{1-2 \nu} \\
& +\frac{\alpha^{3}\left\{r^{-2} A_{311}+A_{312}+A_{313} r^{2}\right\}}{8(1-2 \nu)(1-\nu)\left(P^{2}-4 Q^{2}\right)}=0 \\
& V_{31,11}+\frac{1}{r} V_{31,1}-\frac{2}{r^{2}}\left(U_{31}+V_{31}\right) \\
& -\frac{1}{1-2 \nu} \frac{1}{r}\left\{U_{31,1}+\frac{1}{r}\left(U_{31}+V_{31}\right)\right\} \\
& +\frac{2\left(1-2 \nu-2 \nu^{2}\right) U \alpha^{2}}{1-2 \nu} \\
& +\frac{\alpha^{3}\left\{r^{-2} A_{311}-A_{312}+A_{314} r^{2}\right\}}{8(1-2 \nu)(1-\nu)\left(P^{2}-4 Q^{2}\right)}=0
\end{aligned}
$$

$$
\begin{aligned}
A_{311}= & -19 \nu P^{2} Q^{2}+42 \nu^{2} P^{2} Q^{2}+24 \nu^{3} P^{2} Q^{2} \\
& -32 \nu^{4} P^{2} Q^{2}+28 \nu Q^{4}-72 \nu^{2} Q^{4} \\
& -48 \nu^{3} Q^{4}+32 \nu^{4} Q^{4} \\
A_{312}= & 10 \nu P^{3}-24 \nu^{2} P^{3}-12 \nu^{3} P^{3} \\
& +16 \nu^{4} P^{3}-28 \nu P Q^{2}+48 \nu^{2} P Q^{2} \\
& +36 \nu^{3} P Q^{2}-16 \nu^{4} P Q^{2} \\
A_{313}= & -18 P^{2}+15 \nu P^{2}+88 \nu^{2} P^{2}-32 \nu^{3} P^{2} \\
& -48 \nu^{4} P^{2}+72 Q^{2}+60 \nu Q^{2} \\
& -448 \nu^{2} Q^{2}+8 \nu^{3} Q^{2}+288 \nu^{4} Q^{2} \\
A_{314}= & 6 P^{2}+3 \nu P^{2}-40 \nu^{2} P^{2}+16 \nu^{4} P^{2}-24 Q^{2} \\
& +12 \nu Q^{2}+64 \nu^{2} Q^{2}-24 \nu^{3} Q^{2}+32 \nu^{4} Q^{2}
\end{aligned}
$$

$$
\begin{aligned}
U_{31}= & \frac{1}{2}\left[a_{311} r^{-2}+b_{312} \log r\right. \\
& +\frac{\alpha^{3} A_{311}-8 d_{311}(1-\nu)\left(P^{2}-4 Q^{2}\right)}{16(1-2 \nu)(1-\nu)^{2}\left(P^{2}-4 Q^{2}\right)} \\
& +\left\{a_{312}-\frac{\alpha^{3} A_{312}+8 d_{312}(1-\nu)\left(P^{2}-4 Q^{2}\right)}{16(1-2 \nu)(1-\nu)\left(P^{2}-4 Q^{2}\right)}\right\} r^{2} \\
& +\frac{\left(1-2 \nu-2 \nu^{2}\right) U \alpha^{2}}{1-2 \nu} r^{2} \\
& \left.-\frac{4(1-\nu)\left(7 A_{313}+A_{314}\right)-5\left(3 A_{313}+A_{314}\right)}{1526(1-2 \nu)(1-\nu)^{2}\left(P^{2}-4 Q^{2}\right)} \alpha^{3} r^{4}\right]
\end{aligned}
$$$$
V_{31}=\frac{1}{2}\left[a_{311} r^{-2}-b_{312} \log r\right.
$$$$
+\frac{\alpha^{3} A_{311}-8 d_{311}(1-\nu)\left(P^{2}-4 Q^{2}\right)}{16(1-2 \nu)(1-\nu)^{2}\left(P^{2}-4 Q^{2}\right)}
$$$$
+\left\{a_{312}+\frac{\alpha^{3} A_{312}+8 d_{312}(1-\nu)\left(P^{2}-4 Q^{2}\right)}{16(1-2 \nu)(1-\nu)\left(P^{2}-4 Q^{2}\right)}\right\} r^{2}
$$$$
-\frac{\left(1-2 \nu-2 \nu^{2}\right) U \alpha^{2}}{1-2 \nu} r^{2}
$$$$
\left.-\frac{4(1-\nu)\left(A_{313}+7 A_{314}\right)+\left(3 A_{313}+A_{314}\right)}{1526(1-2 \nu)(1-\nu)^{2}\left(P^{2}-4 Q^{2}\right)} \alpha^{3} r^{4}\right]
$$$$
U=-\frac{\alpha}{8}(3-2 \nu) P
$$$$
a_{311}=-\frac{\alpha^{3}}{96(1-\nu)} \frac{Q^{4}}{P}\left\{\left(3-45 \nu-4 \nu^{2}+28 \nu^{3}\right)\right.
$$$$
\left.-192 \nu\left(1-\nu^{2}\right) A\right\}
$$ 


$$
\begin{aligned}
& d_{311}=\frac{\left(3+\nu+4 \nu^{3}\right) \alpha^{3}}{16(1-2 \nu)} Q^{2} \\
& d_{312}=-\frac{\alpha^{3}}{24(1-\nu)} \frac{Q^{2}}{P}\left\{2\left(6-15 \nu-8 \nu^{2}-10 \nu^{3}+20 \nu^{4}\right)\right. \\
& +3\left(15-51 \nu-18 \nu^{2}-16 \nu^{3}+40 \nu^{4}\right) \\
& \left.-144 \nu\left(1-\nu^{2}\right) A\right\} \\
& a_{312}=\frac{\alpha^{3} A_{312}+8(3-4 \nu)(1-\nu)\left(P^{2}-4 Q^{2}\right) d_{312}}{32(1-2 \nu)(1-\nu)\left(P^{2}-4 Q^{2}\right)} \\
& b_{312}=\frac{-\alpha^{3} A_{333}+8(3-4 \nu)(1-\nu)\left(P^{2}-4 Q^{2}\right) d_{311}}{8(1-2 \nu)(1-\nu)\left(P^{2}-4 Q^{2}\right)} \\
& \rightarrow \alpha^{3}, n=3
\end{aligned}
$$$$
\begin{aligned}
& U_{33,11}+\frac{1}{r} U_{33,1}-\frac{2}{r^{2}}\left(5 U_{33}+3 V_{33}\right) \\
& +\frac{1}{1-2 \nu}\left\{U_{33,1}+\frac{1}{r}\left(U_{33}+3 V_{33}\right)\right\}_{, 1} \\
& +\frac{\alpha^{3}\left\{r^{-4} A_{331}+r^{-2} A_{332}+A_{333} r^{2}\right\}}{4(1-2 \nu)\left(P^{2}-4 Q^{2}\right)}=0
\end{aligned}
$$$$
V_{33,11}+\frac{1}{r} V_{33,1}-\frac{2}{r^{2}}\left(3 U_{33}+5 V_{33}\right)
$$$$
-\frac{1}{1-2 \nu} \frac{3}{r}\left\{U_{33,1}+\frac{1}{r}\left(U_{33}+3 V_{33}\right)\right\}
$$$$
+\frac{\alpha^{3}\left\{r^{-4} A_{331}+r^{-2} A_{334}-A_{333} r^{2}\right\}}{4(1-2 \nu)\left(P^{2}-4 Q^{2}\right)}=0
$$

$$
\begin{aligned}
A_{331}= & 6 \nu P Q^{4}-18 \nu^{2} P Q^{4}-24 \nu^{3} P Q^{4} \\
A_{332}= & -4 \nu P^{2} Q^{2}+12 \nu^{2} P^{2} Q^{2}+16 \nu^{3} P^{2} Q^{2} \\
& +4 \nu Q^{4}-12 \nu^{2} Q^{4}-16 \nu^{3} Q^{4} \\
A_{333}= & -3 P^{2}-3 \nu P^{2}-4 \nu^{2} P^{2}+8 \nu^{3} P^{2}+12 Q^{2} \\
& -36 \nu Q^{2}+16 \nu^{2} Q^{2}+16 \nu^{3} Q^{2} \\
A_{334}= & 20 \nu P^{2} Q^{2}+4 \nu^{2} P^{2} Q^{2}-16 \nu^{3} P^{2} Q^{2} \\
& -20 \nu Q^{4}-4 \nu^{2} Q^{4}+16 \nu^{3} Q^{4}
\end{aligned}
$$

$$
\begin{aligned}
U_{33}= & \frac{1}{2}\left[a_{331} r^{-4}+b_{332} r^{2}\right. \\
& +\left\{b_{331}+\frac{\alpha^{3} A_{331}-12 d_{331}\left(P^{2}-4 Q^{2}\right)}{24(1-2 \nu)\left(P^{2}-4 Q^{2}\right)}\right\} r^{-2} \\
& +\frac{4(1-\nu)\left(5 A_{332}-3 A_{334}\right)-\left(A_{332}-3 A_{334}\right)}{256(1-2 \nu)(1-\nu)\left(P^{2}-4 Q^{2}\right)} \alpha^{3} \\
& \left.+\left\{a_{332}-\frac{\alpha^{3} A_{333}+12 d_{332}\left(P^{2}-4 Q^{2}\right)}{24(1-2 \nu)\left(P^{2}-4 Q^{2}\right)}\right\} r^{4}\right] \\
V_{33}=\frac{1}{2} & {\left[a_{331} r^{-4}-b_{332} r^{2}\right.} \\
& +\left\{-b_{331}+\frac{\alpha^{3} A_{331}-12 d_{331}\left(P^{2}-4 Q^{2}\right)}{24(1-2 \nu)\left(P^{2}-4 Q^{2}\right)}\right\} r^{-2} \\
& -\frac{4(1-\nu)\left(3 A_{332}-5 A_{334}\right)-3\left(A_{332}-3 A_{334}\right)}{256(1-2 \nu)(1-\nu)\left(P^{2}-4 Q^{2}\right)} \alpha^{3} \\
& \left.+\left\{a_{332}+\frac{\alpha^{3} A_{333}+12 d_{332}\left(P^{2}-4 Q^{2}\right)}{24(1-2 \nu)\left(P^{2}-4 Q^{2}\right)}\right\} r^{4}\right] \\
a_{331}= & \frac{3 \alpha^{3}}{8}(1+\nu)(1+2 \nu) \frac{Q^{6}}{P^{2}+2 Q^{2}}\{1+3 A\} \\
b_{332}= & -\frac{\alpha^{3}}{16}(1+\nu) \frac{P Q^{4}}{P^{2}+2 Q^{2}}
\end{aligned}
$$

$$
\begin{aligned}
& \left\{(3+2 \nu) A^{-1}+(15-6 \nu)+18(1-2 \nu) A\right\} \\
& d_{331}=\frac{\alpha^{3}}{4}(1+\nu) \frac{P Q^{4}}{P^{2}+2 Q^{2}} \\
& \left\{\left(3+2 \nu-20 \nu^{2}\right)+6\left(1+2 \nu-12 \nu^{2}\right) A\right\} \\
& d_{332}=\frac{\alpha^{3}}{3} \frac{Q^{2}}{P^{2}+2 Q^{2}} \\
& \left\{\nu\left(1+3 \nu-\nu^{2}\right) A^{-1}+18 \nu\left(1+\nu-\nu^{2}\right)\right. \\
& \left.-9(1+\nu)\left(1-8 \nu+4 \nu^{2}\right) A\right\} \\
& a_{332}=\frac{\alpha^{3} A_{333}+12(3-4 \nu)\left(P^{2}-4 Q^{2}\right) d_{332}}{96(1-2 \nu)\left(P^{2}-4 Q^{2}\right)} \\
& b_{331}=\frac{\alpha^{3} A_{331}-12(3-4 \nu)\left(P^{2}-4 Q^{2}\right) d_{331}}{48(1-2 \nu)\left(P^{2}-4 Q^{2}\right)}
\end{aligned}
$$

得られた解によると, 円筒シェルの内外境界面において応力の符号が 変化しているものがある.これは，シェル厚内において曲けかが生じてい ることを意味するもので注意すべき解であると思われる.

\section{1. 解形状}

ここで, 解形状の一例を示しておく. 初期形状の平均半径 $r_{0}$ を 1 , シェル厚 $t_{0}$ を 0.2 , 円筒長さを 5 とし, ポアンン比 0.3 の鎆を想定 している. 図は曲け荷重 $M_{0}$ に関するパラメータ $\alpha\left(=M_{0} / E I\right)$ が $0, \pi / 12, \pi / 6, \pi / 4$ となるように曲げを作用させたものを左より示し たものである. ただし，このモデルにおける座届荷重は次節によると $\alpha \doteqdot \pi / 28$ であるが, その変形量はかなり微小であるため, ここでは变 形後の様子を知るために初期形状と座届後の変形形状を示していること になる.
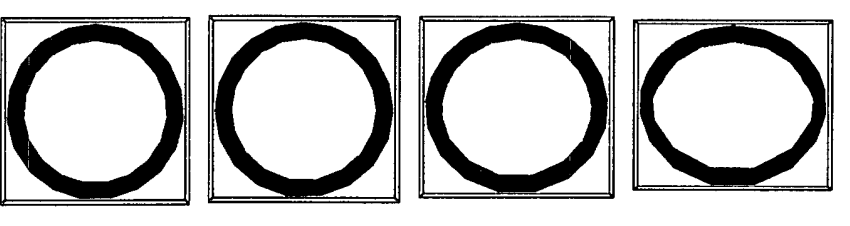

図一 3: 断面変形の様子

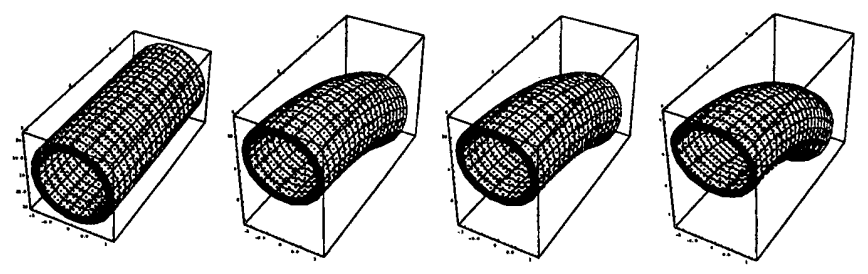

図-4: 全体変形の様子

\section{5. 円筒シェルの破壊}

\section{1. 屈服座届について}

シェルに曲げ荷重を加えていくとモーメントは増加するが, 円筒シェ ルの断面変形に伴う刚性の低下からモーメントが臨界点に達する.ここ では幾何学的非線形解によるモーメントを求め，モーメントの烸界值お 
よび座屈荷重から届服座屈に関する考察をおこなう。

$$
\begin{aligned}
M= & \int_{0}^{2 \pi} \int_{r_{1}}^{r_{2}} \sigma_{33}\left(x-x_{0}\right) r d \theta d r \\
\sigma_{33}= & \sigma_{3311} \cos \theta+\sigma_{3320}+\sigma_{3322} \cos 2 \theta \\
& +\sigma_{3331} \cos \theta+\sigma_{3333} \cos 3 \theta
\end{aligned}
$$

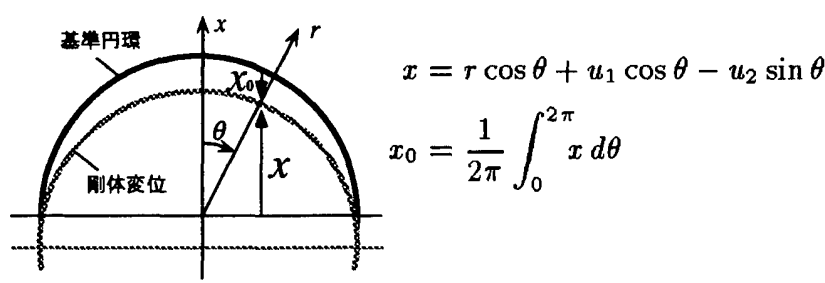

図ー5: 夙体変位による中立軸のずれ

$x$ は基準の円環における中立軸からの距離であるが，円環の曲率半径 の変化を考庙したことによる用体変位成分を含んでおり，中立軸は基準 の円環軸からずれる.ここでは $x$ 方向变位の平均量 $x_{0}$ を用いることで ずれを補正してモーメントを求めている．また，㴊体変位で生じる円琮 軸方向応力からくるモーメントは $E r_{0}{ }^{5} t_{0} \alpha^{3}$ を俰数にもっているが, 式 (17)から分かるように殆ど影響がない，よって，各次数ごとに殆ど影響 のない項を省略して近似的に得たモーメントを次に示す.

$$
\begin{aligned}
M \doteqdot & \pi E r_{0}{ }^{3} t_{0} \alpha-\frac{3}{2} \pi E\left(1-\nu^{2}\right) \frac{r_{0}{ }^{7}}{t_{0}} \alpha^{3} \\
& +\frac{5}{8} \pi E\left(1-\nu^{2}\right)^{2} \frac{r_{0}{ }^{11}}{t_{0}{ }^{3}} \alpha^{5}
\end{aligned}
$$

式 (16) による簪密解に比べと近似解惊高めの值を示す傾向にある が, 通常のシェルではその䛊差は無視できる程度である. そこで, 式(17) によるモーメントが極大值をとるとき円筒シェルは屈服座屈を引き起こ すとして, モーメントの踟界值 $M_{C R}\left(=M_{\text {max }}\right)$ および屈服座屈時の 曲け荷重によるパラメータ $\alpha\left(=M_{0} / E I\right)$ を炊に示す。

$$
\begin{aligned}
M_{C R} & =\frac{23+3 \sqrt{31}}{625} \sqrt{\frac{8(9-\sqrt{31})}{1-\nu^{2}}} \pi E r_{0} t_{0}{ }^{2} \\
\alpha & =\frac{1}{5} \sqrt{\frac{2(9-\sqrt{31})}{1-\nu^{2}}} \frac{t_{0}}{r_{0}^{2}}
\end{aligned}
$$

さらに座届点を知るだけならば，簡易的に用いることができるという 点においても $\alpha^{3}$ の項までを考慮すれはよい，このような考えのもとに， $\alpha^{3}$ までについて求めた場合は次のようになり，その座屈荷重は式 (17) によるものより若干低くなる.

$$
\begin{gathered}
M \doteqdot \pi E r_{0}{ }^{3} t_{0} \alpha-\frac{3}{4} \pi E\left(1-\nu^{2}\right) \frac{r_{0}{ }^{7}}{t_{0}} \alpha^{3} \\
M_{C R}=\frac{4}{9 \sqrt{1-\nu^{2}}} \pi E r_{0} t_{0}^{2} \\
\alpha=\frac{2}{3 \sqrt{1-\nu^{2}}} \frac{t_{0}}{r_{0}^{2}}
\end{gathered}
$$

これより順曲げの作用する円筒シェルの屈服座屈荷重は初期形状およ び材料特性から直ちに得られ，全体破壊の判定に用いることができると 同時に座屈時の変形状態も前節による变位解より知る事ができる. また 近似解においては，シェル理論による座屈荷重 4 ）とほぼ一致している.

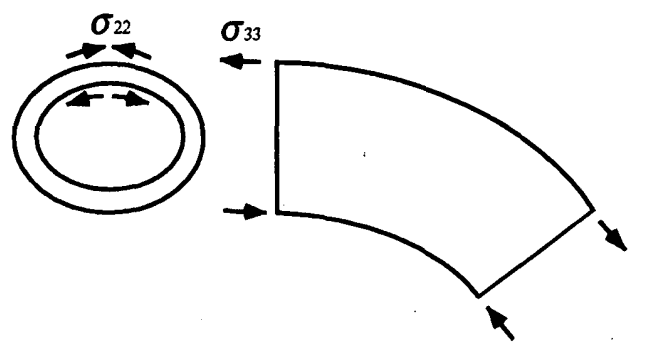

図一 6: 応力 $\sigma_{22}, \sigma_{33}$

$$
Y=\sqrt{\frac{1}{2}\left\{\left(\sigma_{33}-\sigma_{22}\right)^{2}+\sigma_{33}{ }^{2}+\sigma_{22}{ }^{2}\right\}}
$$

\section{2. 局所的応力の降伏について}

ここでは, 局所的な応力の降伏による円筒シェルの破壊について Mises の降伏条件 5) を用いて考察している. 具体的には, 円筒シェルの風服 座屈時†の応力状態で材料の塑性化が発生する場合のシェル厚と断面半 径との関保について検討している.ここで，内外境界面は自由面であり 境界面における応力 $\sigma_{11}, \sigma_{12}$ は零となるため, シェルの厚さ内において もそれらの応力はほほ零と考えられる. したがって, 主要な応力は $\sigma_{22}$ と $\sigma_{33}$ であるとして Mises の降伏応力を図一6のように表わす.

断面内において降伏応力が最大となるのは伸び側 $(\theta=0)$ の外側表 面 $\left(r=r_{2}\right)$ であり, 軸方向において引張り $\left(\sigma_{33}>0\right)$ リング方向に 王䈹 $\left(\sigma_{22}<0\right)$ が影著に現れている.

ここで, 普通鎆（ヤング率: $2.1 \times 10^{6} \mathrm{kgf} / \mathrm{cm}^{2}$, ポアソン比 : 0.3 ）において，外㑡表面の応力分布を図一 7 に示しておく：ここでは, 円 周方向 $\theta(0 \sim 2 \pi)$ とシェル厚・平均半径比 $t_{0} / r_{0}(0 \sim 1 / 1000)$ をパラ メータにとり，上から順に $\alpha$ のみを考慮， $\alpha^{2}$ までを考慮，及び $\alpha^{3}$ ま でを考虑した主応力を用いて Mises の降伏応力分布を表示している.こ れによると, 線形解では $\sigma_{33}$ のみ存在するため上下の縁で同等の応力 状態になるが，何学的非線形項を考慮した場合には $\sigma_{22}$ の影響，すな わち棈円化による応力状笂への影繁がみられる。

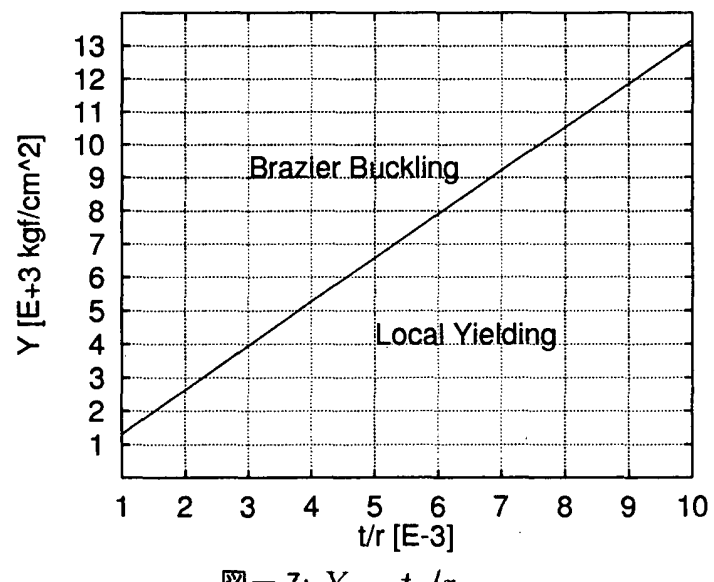

図-7: $Y-t_{0} / r_{0}$

また, シェルが厚くなるに従って Mises 応力はほぼ線形的に㙕加し ていくことがわかるため, 最も応力の卓越している $\theta=0$ に限定して Mises の降伏応力 $Y$ とシェル厚・平均半径比 $t_{0} / r_{0}$ との関係を図一 7

\footnotetext{
†式（17）による屈服座屈時としている
} 
に示し, 円筒シェルの破摄が屈服座屈の先行によるものか, 局所的応力 の降伏によるものかを明らかにしている.

例として平均半径 1 に対してシェル厚が $1.82 \times 10^{-3}$ (F值： $\left.2400 \mathrm{~kg} / \mathrm{cm}^{2}\right), 3.11 \times 10^{-3}\left(F\right.$ 值: $\left.4100 \mathrm{kgf} / \mathrm{cm}^{2}\right)$ より厚くなると, 局部において忘力が弾性限界を越え塑性流動しシェルが破埴に至ること になる. その境界值は $F$ 值を用いて次式より近似的に得られる.

$$
\frac{t_{0}}{r_{0}} \doteqdot 7.6 \times 10^{-7} \mathrm{~F}
$$

以上の結果より，通常の厚さの円筒シェルでも応力の降伏により材料

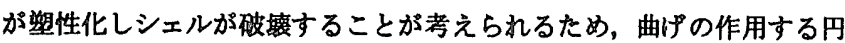
筒シェルでは届服座屈のみならず局所的な応力の降伏についても検討す る必要がある。
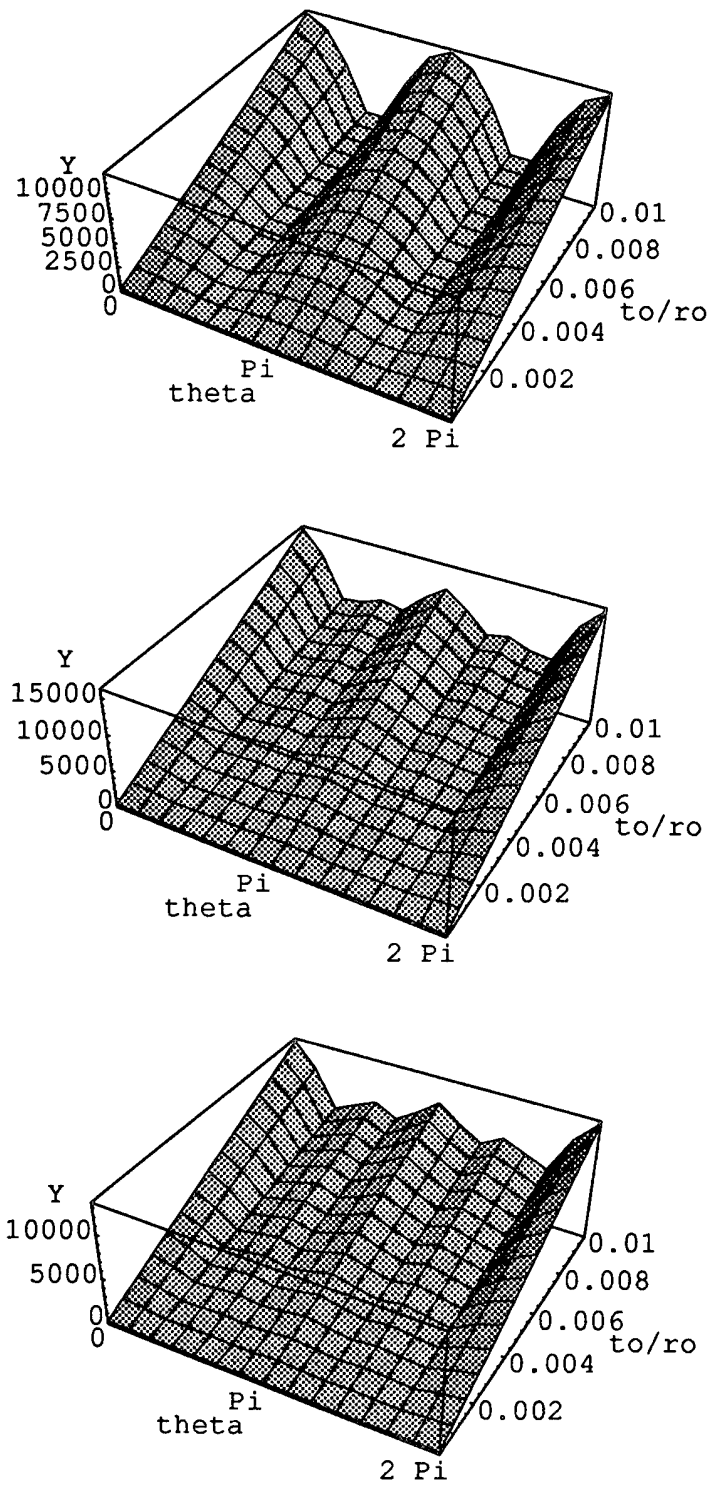

図一 8: Mises 応力分布

\section{6. 結語}

本論文では純曲け゚の作用する閉断面円简シェルを例に，3 次 元弾性論によるシェルの有限変形解析をおこない, シェルの座 届につき検即した。その結果とまとめを次に示す。

1. 有限変形解析をおこなう場合, 近似的に考えられる形状を 基準として解析をおこなうことが有効である．本論文にお いては，純曲け゚の作用する円筒シェルに対して近似形状で ある円環を基準座標に採り，その妥当性を示した.

以上から，本踚文で提案した方法により 3 次元有限変形解 析における理論解を简潔に得ることができるといえる.

2. 極薄円筒シェルにおいてのみ屈服座届の先行によるシェル の破壊がみられ, 通常の円筒シェルでは純曲げによる軸応 力と円形断面の棈円化に伴う曲げ応力の組み合わせにより 降伏応力に至ることが先行することでシェルが破壊すると いう結果を得た。

したがって，極薄シェルにおいては届服座届の検討はシェ ル理論によって行えば充分である (もちろん本解析で得ら れた解によっても検討可能である). しかし，通常のシェル や厚肉シェルにおいては材料の塑性化によるシェルの破壊 が考えられることから，3次元解析などによる局所的な応 カの検討が必要である.

ここで得られた解は限定的な変形に対する理論解ではあるが，有 限要素法などの数值解析法における解の比較対象として用いるこ とや，要素の決定などに関するめやすにすることが考えられる．

\section{参考文敨}

1) Fung,Y.C. 大㛢 義夫 訳 : 固体の力学/理論, 倍風館, 1970

2) Flügge,W. 後藤 学 訳 : テンソル解析と連続体力学, プレイン図毒（丸 善)，1979

3）多谷虎男：力学におけるテンソルと峦分解析 [上], 学会出版センター, 1980

4）長柱研究委員会（林 媇）：弾性安定要筧（第 5 編 款），コロナ社，1951

5) 山田嘉昭：塑性力学, 日刊工慈新閏社, 1965

6) 松岡 理 : シェルの三次元解析 (空間構造 第一巻)，呯井善勝 記念鯆演会 実行委員会, 1993

7）松岡 理 山田耕司 松井 徹哉 大森 博司：円筒シェルの軸対称曲げ圭力 問題の三次元理論解析（日本建築学会構造系論文集 第 460 号, 83-91，1994 年 6 月)

8) 山田耕司 松网 理 松井 徹哉 大森博司 : 純曲伊の作用する閉断面円筒 シェルの三次元有限理論解析（日本建築学会構造系論文集 第 468 号, 81-89, 1995 年 2 月)

9）山田耕司 松岡理 松井徹哉 大棵 博司：円简シェルの非軸対称曲げ忘 力問題の三次元理論解析 (日本建叠学会構造系論文集 第 474 号, 127-136 1995 年 8 月)

10）松岡理 山田耕司上村 充筑：三次元有限変形解析とキルヒホフ忘力 （日本建築学会大会学街講演梗概集 1993）

11）松岡理 山田耕司 上村充範 : 純曲げの作用する緥型円简シェルの有限 変形解析（日本建築学会大会学術講演梗概集 1993）

12）松岡 理 上村 充笨 山田 耕司：純曲恬の作用する円简シェルの円環を基準 形状とする三次元有限変形解析（日本建築学会大会学淮講演梗概集 1994）

13) Matsuoka,O. Yamada,K. : Three Dimentional Non-Linear Elastic Analysis of a Circular Cylindrical Shell Subjected to Pure Bend ing, Proceedings of the Seiken-IASS Symposium, 1993.pp.45-52

14）松岡理 上村充範 山田耕司：純曲げの作用する円简シェルの変形後の 円頊形状を基準とする 3 饮元有限变形解析（第 13 回 海洋工学シンポジウム 1995 年 7 月) 